\title{
How to Achieve Full Potential of Scientific Research
}

\section{Nair SS}

Government of India Ministry of Health and Family Welfare, Bangalore, Karnataka, India

*Corresponding author: Nair SS, Government of India Ministry of Health and Family Welfare, 618, $3^{\text {rd }}$ Cross, $3^{\text {rd }}$ Block, Bangalore, Karnataka, India, Tel: 918025532371; E-mail: forte.nair@gmail.com

Received date: August 28, 2015; Accepted date: October 13, 2015; Published date: October 18, 2015

Copyright: (c) 2015 Nair SS. This is an open-access article distributed under the terms of the Creative Commons Attribution License, which permits unrestricted use, distribution, and reproduction in any medium, provided the original author and source are credited.

\begin{abstract}
Research plays an essential role in development of science. This paper gives the main reasons for not achieving full potential of research to reduce human suffering (the objective of clinical research). Some examples are given to illustrate these reasons. Publication of findings from research and evaluation studies and open discussion of the findings leave much to be desired. Importance of publishing research papers quickly and utilization of findings are emphasized. To overcome all obstacles for good quality scientific research, it suggests that National and International Research Authorities staffed by scientists with open mind and broad vision should be set up to constantly review funding of research and utilization of research findings and to suggest further meaningful research. It points out that defective education is a basic general obstacle for development of scientific research. It recalls the exhortation by Einstein that "The important thing is not to stop questioning" and stresses that we can make progress only if we ask lot of questions, discuss these freely and objectively and carry out scientific studies to find proper answers.
\end{abstract}

\section{Introduction}

Research plays an essential role in development of science. This paper focuses on some problems which hinder achievement of full potential of scientific research to reduce human suffering (the objective of clinical research) and how these can be overcome. Most examples given to illustrate problems are from field of tuberculosis with which the author has been involved for a long time. However, most of these are likely to be relevant for many other scientific fields also.

Main reasons for not achieving full potential of research to reduce human suffering are: (1) lack of ethics of care, (2) lack of open mind resulting in single track approaches, (3) complacency which prevents innovative research (4) obstructions and diversions due to prejudice and vested interests, (5) lack of efforts to sharpen tools, (6) scientific dishonesty and (7) non-utilization of research findings.

Number of studies has been carried out to ascertain cure rate among tuberculosis $(\mathrm{TB})$ patients who had completed prescribed treatments with different regimens. Though data for those not completing treatment were also collected in these studies, these were ignored because of single track approach to ascertain cure rate for these regimens. Subsequent analysis of these ignored data [1] gave a very important finding that about two-thirds of those not completing treatment were also cured. Other studies [2-4] had shown that about $25 \%$ to $33 \%$ of cases had cure without known scientific treatment. Though these two groups overlap, it is evident that at least two thirds of cases did not need the full treatment which was imposed on them. But, due to lack of vision and ethics of care, no attempts have been made to carry out research to avoid this unethical treatment. A possible investigation suggested [1] to identify cases needing no treatment, partial treatment and full treatment has been ignored because of lack of an ethics of care and open mind.

Research workers have to concentrate on their scientific studies. But this concentration should not result in a single track approach which misses important abnormal occurrences and thereby misses possibilities for further research. In another example, an experiment conducted by one of my colleagues was considered a failure because some observations contradicted the current belief. When he delved deeper on the discordant observations in his experiment (as suggested by me) some startling findings came to light. This also emphasizes need for an open mind. When discordant observations come up these should not be considered as errors without deeper investigations.

Diagnosis based on X-ray examination has been in vogue for a long time. As far back as in 1974 , one study [5] showed that $87 \%$ of those diagnosed on X-ray examination alone are unlikely to have TB. This important finding was not utilized or examined further because of lack of open mind. Enormity of this problem was emphasized by an indepth evaluation study [6] in 1988 which showed that on an average, 700,000 cases were diagnosed by X-ray examination every year, of whom about $600,000(87 \%)$ were unlikely to be suffering from TB. It recommended that repeated sputum examination should be the main criterion for diagnosis of TB. Following this, Revised National Tuberculosis Control Programme (RNTCP) emphasized importance of repeated sputum examination. Still, reported figures for RNTCP case detection showed that in 2006, 2008 and 2009 only 13\% were smear positive among cases diagnosed on $\mathrm{X}$-ray alone and repeatedly confirmed that about $87 \%$ of those diagnosed on X-ray alone were not likely to be true cases of tuberculosis. Private practitioners throughout the country rely mainly on X-ray examination for diagnosing TB. These unscientific practices by government and private health institutions together resulted in even more enormous wrong diagnosis and huge wastage of drugs and X-ray facilities every year. Even more important, this caused mental agony and permanent social problems to millions of people wrongly diagnosed as having TB, and their families. But, both these unscientific and inhuman aspects were overlooked due to lack of ethics of care and serious attempts to carry out research to overcome these have not been made. Surprisingly, Medical Council of India ignored these findings due to lack of ethics of care and open mind. It ought to have insisted that X-ray examination which results in colossal wrong diagnosis should not be "prescribed" by any registered 
Page 2 of 3

medical practitioner for diagnosing TB and instead repeated sputum microscopy should be carried out.

For many years, hardly any worthwhile attempt has been made to effect technological improvements for diagnosing $\mathrm{TB}$ by $\mathrm{X}$-ray examination. VA Menon (retired X-ray Engineer, National Tuberculosis Institute, India) has been unsuccessfully knocking at doors of number of scientific bodies for more than 25 years for funds to carry out a project for technological improvements! Lack of vision to carryout innovative research to sharpen tools is obvious. Obstruction due to prejudice and vested interests may also have played a part. Utmost urgency has to be given to conduct research to develop better tools to diagnose cases which cannot be detected by direct smear examination.

It is encouraging that a new technique (Xpert MTB/RIF) which can diagnose more cases than sputum microscopy has been developed [7]. Large scale application of this technique will have to depend on final results of experiments on sensitivity and specificity of this technique for diagnosing $\mathrm{TB}$ and whether it can be applied throughout the country by government and private health institutions to provide benefit to common people.

Large numbers of tools have been developed and are in use to diagnose various diseases. It is doubtful whether sensitivity and specificity tests (similar to those for X-ray examination and sputum microscopy for diagnosing TB) have been conducted for all. If not, unsuspected wrong diagnosis may be occurring quite often, showing lack of ethics of care. How far these tools being used repeatedly has led to complacency and prevented development of improved tools is another important question. Development of costly diagnostic tools are no doubt scientific achievements but it is a matter of concern that the resultant complacency and lack of ethics of care seem to be standing in the way of developing tools which common people at grass root level can afford to use.

Case detection under RNTCP is based on diagnostic examinations of outpatients with complaints of chest problems visiting health facilities. Even if this method succeeds in practice in detecting all TB cases among them, only about $10 \%$ of these relief seeking chest symptomatics, who are likely to be suffering from $\mathrm{TB}$, can be diagnosed and treated. No specific treatment is given to the remaining $90 \%$ of sufferers who are knocking at the doors of health facilities with chest problems [1]. Due lack of ethics of care and open mind serious attempts have not been made to conduct research for providing proper diagnosis and treatment to millions of people with other chest diseases who present themselves with symptoms. This neglect exists despite the fact that it seriously affects popularity of health facilities and thereby hinders case detection under RNTCP.

Journals often publish articles with fairly similar findings. While these repetitions serve the purpose of providing confirmations, this criterion should not stand in the way of publishing articles which question known "beliefs".

Publication of findings from research and evaluation studies and open discussion of the findings leave much to be desired [8]. Invariably, the time gap between the period to which the information relates and publication of the findings is far too long to be of interest and follow up action. This slows down utilization of research findings. To reduce the time gap, research workers have to speed up preparation of papers or reports and submit these quickly to organizations which publish research findings.
The latter ought to minimize the duration from receipt of papers to their review and publication. Papers rejected by one journal being published in another are not uncommon and shows selectivity and lack of objectivity in reviewing. Reviewers selected by journals should be asked to be objective to avoid prejudices and to encourage innovation in research.

For speedier communication of findings, all publishing organizations should set up web sites to which papers, summary reports and even full reports could be submitted through e-mail [8]. Their reviewers (with computer facility) could quickly review the material on line. Those that are cleared by the reviewers could be published in another web site. This web site may be open to all or only to their subscribers. The site could also list the brief summaries of the papers and reports not cleared by the reviewers as well as postal and email addresses of the authors so that interested research workers could contact them and make themselves fully aware of the work already carried out and its limitations, while undertaking their own research.

Research is funded by organizations set up by governments, United Nations, philanthropists and corporate bodies. There is no uniformity in the standards and procedures adopted for funding research. Often who applies for funds is given more importance than the importance of the subject for research. This prejudiced approach does not encourage new research workers.

Funding organizations generally lack in commitment to research. This affects their advocacy efforts to get sufficient funds. They sometimes sanction research projects to satisfy popular demands or to distribute favours. Moreover, due to lack of commitment and vision, findings from research are often ignored. Large number of scientists has put in lot of efforts to carry out research and huge amount of funds have been spent. But most of these have been wasted because findings were not utilized. Why spend enormous amounts of money on research if the findings will not be utilized?

Some organizations indulge in paid research to bring out results which will help their selfish or commercial interests. These are examples of scientific dishonesty. Reviews of RNTCP tend to be "selectively objective", suggesting a degree of scientific dishonesty [1]. For instance, WHO's 2000 Joint Tuberculosis Programme Review of India [9] gives a rosy picture under the executive summary while reporting a number of negative findings under the full text. WHO's 2003 Joint Tuberculosis Programme Review [10] reported that a significant number of patients diagnosed at government health facilities are not registered or offered RNTCP regimens. But the report did not mention the actual proportion, though this is important, probably for hiding a weakness of RNTCP. A mechanism has to be found to expose scientific dishonesty.

To overcome all such obstacles for good quality scientific research discussed above, National and International Research Authorities staffed by scientists with open mind and broad vision should be set up to constantly review funding of research and utilization of research findings and to suggest further meaningful research. Their recommendations should be fully accepted and implemented by all governments if they are serious about encouraging scientific research of good quality.

A basic general obstacle for development of scientific research is defective education [11]. Adequate attention is not given to development of analytical/logical thinking. Often, theory alone is taught first and its application later (if at all) instead of sandwiching theory and application in suitable stages in an intelligent manner. 
Page 3 of 3

Attempts to dovetail aptitude with selection of fields for education and skill development are scarce. This often resulted in calamity of round things being squeezed into square plugs. Research and development $(\mathrm{R}$ and D) jobs are often taken up by persons without any aptitude for or interest in these but only to earn a salary. This result in slow or no contribution to $\mathrm{R}$ and $\mathrm{D}$. Holistic education suggested in the article 11 will build up an environment conducive to development of scientific research.

We can make progress only if we ask lot of questions, discuss these freely and objectively and carry out scientific studies to find the proper answers [8]. By its very nature, top level of any government organization will not encourage questions being asked. Neither will they, on their own, ask questions or listen to questions being asked. If they do, it is mostly for filling exposed information gaps or to meet popular demands. To fill these gaps, they either provide funds to scientific organizations or order lower functioning levels to carry out studies that they (or some pressure groups) think are needed or ask them to come up with proposals for studies to find the answers. The scope for these organizations to ask questions is extremely limited. Moreover, even if they ask questions, they may either be not actually relevant to the development needs or may be deemed to be so by the programme authorities, more often the latter. Most such studies by these organizations would then be a waste of time and efforts. These are serious blocks that stand in the way of asking questions that are vital for overall progress in science and development.

While asking questions we should not take the attitude of a frog in the well, for which universe consists of the well only. We have to ask lot of questions within and beyond the well, with an open mind and without being influenced by any pressure groups or pressure of circumstances. If we do not ask searching questions we cannot have a scientific - cum - practical approach, which is essential for progress. Any problem and actions needed to overcome it are interconnected with other problems. The questions asked should cover wide fields so that none of the interactions are missed. Should we not adopt this approach which would give a wider and clearer vision?

I have asked a number of questions and also provided answers to some, based on available facts that I know of. May be, more questions should be asked and answers found for all of them by well-planned studies. Some of us may hesitate to ask questions because of a pessimistic attitude that nothing will come out of it. Will this silence help? Asking questions will at least help all of us to have a clearer vision and repeated questioning will produce results. As Einstein said "The important thing is not to stop questioning".

\section{References}

1. Nair SS (2011) Ethical Aspects of Revised National Tuberculosis Programme. Ind J Med Ethics 8: 102-106.

2. National Tuberculosis Institute (1974) Tuberculosis in a rural population of South India - a five-year epidemiological study. Bull World Health Organ 51: 473.

3. Baily GVJ, Samuel GE, Nagpaul DR (1974) A concurrent comparison of an unsupervised self-administered daily regimen and fully supervised twice weekly regimen of chemotherapy in a routine out-patient treatment programme. Ind J Tub 21: 152-167.

4. Gothi GD, Chakraborty AK, Parthasarathy K, Krishnamurthy VV (1978) Incidence of pulmonary tuberculosis and change in bacteriological status of cases at shorter intervals. Indian J Med Res 68: 564-574.

5. Nair SS (1974) Significance of patients with X-ray evidence of active tuberculosis not bacteriologically confirmed. Ind J Tub 21: 3-5.

6. In-depth study of NTP in India (1988) Institute of Communication, Operations Research and Community Involvement (ICORCI). ICORCI, Bangalore, India.

7. Sachdeva KS, Raizada N, Sreenivas A, Van't Hoog AH, van den Hof S, et al. (2015) Use of Xpert MTB/RIF in Decentralized Public Health Settings and Its Effect on Pulmonary TB and DR-TB Case Finding in India. Plos One 10: $\mathrm{e} 0126065$.

8. Nair SS (2002) Are We Asking Enough Questions? Dr. P V Benjamin Oration at Karnataka State Tuberculosis Workers' Conference.

9. World Health Organization (2002) Joint Tuberculosis Programme Review, India, February 2000. WHO-SEARO, New Delhi, India.

10. World Health Organization (2004) Joint Tuberculosis Programme Review, India, September 2003. WHO-SEARO, New Delhi, India.

11. Let us Think and Act with an Open Mind to Develop a Vibrant Democracy - SRB: Article 25. 